\title{
La materialidad de las operaciones económicas para efectos fiscales en México
}

The materiality of economic operations for tax purposes in Mexico

A materialidade das operações econômicas para efeitos fiscais no México

\author{
José Manuel Osorio Atondo \\ jose.osorio@ues.mx \\ Universidad Estatal de Sonora - México \\ https://orcid.org/0000-0001-8508-9953
}

\author{
Jesús María Martín Terán Gastélum \\ martin.teran@ues.mx \\ Universidad Estatal de Sonora - México \\ https://orcid.org/0000-0003-2312-0294
}

\begin{abstract}
RESUMEN
En el presente estudio, se expone un análisis jurídico fiscal nacional en correlación a una de las reformas estructurales efectuadas al Código Fiscal de la Federación mediante la adición de su artículo 69-B y que entró en vigor en enero del 2014. Modificación legislativa orientada en la presunción y otras facultades de la autoridad fiscal a detectar operaciones económicas inexistentes manifestadas en los comprobantes fiscales emitidos por los contribuyentes, al carecer de la materialidad sustancial económica o razón de negocios; en búsqueda con ello de combatir la evasión fiscal, el lavado de dinero y por ende la defraudación. En atención al examen efectuado, se exhibe la congruencia de la exposición de motivos de la iniciativa, la aplicación de la reforma y el tratamiento de los datos estadísticos emitidos por el Servicio de Administración Tributaria al mes de agosto del 2021, escenario en el cual se ha adoptado un nuevo paradigma en el sistema tributario y fiscal en México.
\end{abstract}

Palabras clave: Evasión fiscal, facultad de presunción, materialidad de operaciones económicas, operaciones económicas inexistentes, comprobantes fiscales digitales por internet.

\begin{abstract}
This study provides a legal analysis of the structural reforms made to the Federation Tax Code, specifically regarding the effects of the addition of Article 69-B, which took effect in January 2014. This legislative amendment provides powers or faculties to the tax authority, including presumption of illicit activity regarding non-existent economic transactions reported in tax receipts by taxpayers to the tax authority. Because these operations lack substantive economic materiality or business purpose, they can serve the tax authority in the detection of tax evasion, money laundering and fraud. The examination performed in this study validates the congruence of the reform's purpose (as explained in a memorandum issued at the time of promulgation) with both the processing of the statistical data issued by the Tax Administration Service covering January 2014 to august 2021 and enforcement of the reform during this period.
\end{abstract}

Keywords: Tax evasion, faculty/power of presumption, materiality of economic operations, non-existent economic transactions, digital tax receipts online.

\section{RESUMO}

Neste estudo, expõe-se uma análise jurídica-fiscal nacional em correlação com uma das reformas estruturais efetuadas no Código Fiscal da Federação, através da adição do artigo 69-B e que entrou em vigor em janeiro de 2014. Trata-se de uma modificação legislativa orientada na presunção e outras faculdades da autoridade fiscal para detectar operações econômicas inexistentes, manifestadas nos comprovantes fiscais emitidos pelos contribuintes, por carecerem da materialidade substancial econômica ou razão de negócios. Busca-se, com isso, combater a evasão fiscal, a lavagem de dinheiro e por consequência, a fraude. Em resposta ao exame efetuado, exibe-se a congruência da exposição de motivos da iniciativa, a aplicação da reforma e o tratamento dos dados estatísticos emitidos pelo Serviço de Administração Tributária no mês de agosto de 2021, cenário no qual foi adotado um novo paradigma no sistema tributário e fiscal no México.

Palavras chave: Evasão fiscal, faculdade de presunção, materialidade de operações econômicas, operações econômicas inexistentes, comprovantes fiscais digitais por internet. 


\section{INTRODUCCIÓN}

Uno de los tópicos máximamente analizados en la actualidad lo personifica lo relativo a las gestiones en las políticas económicas de los Estados, quienes a través del instrumento denominado política fiscal y en atención a su marco jurídico doméstico realizan cambios estructurales y de fondo en las normas jurídicas tributarias; con el objeto de realizar acciones orientadas al mejoramiento de las finanzas públicas , tanto en la obtención del ingreso, la administración de los recursos obtenidos y en la ejecución del gasto público.

Tal es el caso que, en la mayoría de los países, principalmente en América Latina (AL); podemos detectar en las últimas décadas una serie de modificaciones en las normas tributarias que establecen la obligatoriedad de contribuir al gasto público; reformas alineadas a incrementar el número de contribuyentes mediante el uso de estrategias para el combate a la informalidad o bien, cambios en algún elemento esencial del tributo como la base gravable, la tasa o tarifa aplicable.

Asimismo, mediante la implementación de las Tecnologías de la Información y Comunicación (TIC's) en las administraciones tributarias o hacendarias se han ejecutado herramientas tecnológicas con el objetivo del intercambio de información entre los gobiernos y la detección de actos tipificados como ilícitos, tales como la evasión fiscal, el lavado de dinero, entre otros. Precisamente al respecto, se exhibe en el presente estudio una de las reformas legales a uno de los principales ordenamientos jurídicos en México, exponiéndose la aplicación de las facultades de presunción de parte de la autoridad para detectar la posible inexistencia de las operaciones amparadas en comprobantes fiscales y sus consecuencias jurídicas tanto para el emisor como para el receptor de los mismos al no comprobar la materialidad de sustancia económica o razón de negocio.

\section{FUNDAMENTACIÓN TEÓRICA}

\subsection{La potestad tributaria del Estado mexicano.}

Gracias a la convivencia humana y por ende del surgimiento de las necesidades colectivas en sociedad, los Estados requieren de los individuos, recursos económicos para estar en la posibilidad de su existencia como tal y de sufragar los gastos públicos demandados en colectividad (Venegas, 2010). Para ello, los mismos gobernados a través de la Constitución jurídica del país en que radican, así como mediante leyes, otorgan facultades para que el gobierno quien es instaurado o electo por su población a fin de que reglamente, controle y administre recursos para que abastezcan las necesidades sociales (Dorantes \& Gómez, 2014); así como el Estado en su conjunto con apoyo en su actividad financiera realice a través de instrumentos legales en la disciplina de las finanzas públicas, acciones orientadas en la captación de ingresos pecuniarios, la ejecución del gasto público (Mendoza, et al., 2017), el manejo conveniente de los recursos recaudados, el sostenimiento del aparato estatal y la realización de la justicia individual, mutua y colectiva (Carrasco, 2017).

Por tal motivo en primer lugar, al Estado se le confiere legalmente su irrenunciable potestad tributaria para que a través del Poder Legislativo emanen normas jurídicas que establezcan cargas fiscales a los particulares, gravando el ingreso, la utilidad o consumo en atención a los elementos esenciales del gravamen; tales como el sujeto, el objeto, la base, la tasa o tarifa y dando cumplimiento de esta manera con el principio de legalidad.

En segundo lugar, mediante el Poder Ejecutivo aplica la norma tributaria, facilita en la esfera administrativa para su acatamiento y en ocasiones solucionar las controversias que surjan entre la Administración y los gobernados en el proceso de la interpretación o ejecución de la ley. En tercer lugar, por medio del Poder Judicial puede arbitrar las impugnaciones entre la Administración y el gobernado o entre el Poder Legislativo y el gobernado sobre la legalidad o constitucionalidad de la actuación de los tres poderes (Rodríguez, 2011). 
Ante tal escenario, la obligación de contribuir para el sustento de los gastos públicos, tiene su génesis en la propia existencia del Estado como una sociedad que demanda los medios para estar en las condiciones de cumplir con las funciones que se le confieren (García, 2020), por lo que hay fisco federal en tanto el ente económico intitulado como Estado funge como el titular de un patrimonio que debe ser amplificado con las aportaciones denominadas como contribuciones (Torres, 2016).

Para el caso que nos ocupa, dicha potestad del Estado y/o relación jurídica tributaria entre el sujeto activo y sujeto pasivo, se instituye desde la Constitución Política de los Estados Unidos Mexicanos (CPEUM) en su artículo 31 fracción IV, mismo que a la letra señala "son obligaciones de los mexicanos... contribuir para los gastos públicos, así de la Federación, como de los Estados, de la Ciudad de México y del Municipio en que residan, de la manera proporcional y equitativa que dispongan las leyes".

Tal es el caso que entre las principales fuentes de financiamiento del gasto público en México, en atención al ciclo presupuestario de cada ejercicio fiscal, en la etapa de la presupuestación del ingreso, la sección económicamente más importante en la Ley de Ingresos de la Federación (LIF), lo simboliza el apartado denominado "Ingresos del Gobierno Federal"; clasificación que exhibe las percepción económica de las diferentes contribuciones proyectadas, sobresaliendo en la misma, el rubro de "impuestos" en donde se puede visualizar la importancia porcentual que representa el Impuesto Sobre la Renta (ISR), el Impuesto al valor Agregado (IVA) y el Impuesto Especial Sobre Producción y Servicios (IEPS) en correspondencia a las demás percepciones programadas, figurando la sumas de los tres gravámenes, en más del 50\% en los últimos tres ejercicios fiscales en correlación al monto total manifestado en la Ley en comento (Osorio y Osorio, 2019).

\subsection{La evasión fiscal y el lavado de dinero, un acercamiento.}

Indiscutiblemente, la implementación de las TIC's por parte de las administraciones tributarias de varios países han causado un nuevo paradigma en el cumplimiento de las obligaciones fiscales, en virtud que, al optimizar los medios de comunicación entre el sujeto activo y pasivo de la relación jurídica tributaria se ha favorecido en la minimización de costos para dichas instancias gubernamentales. Sin embargo, cabe señalar que uno de los principales motivos en su ejecución ha sido el de combatir actos ilícitos, tales como la evasión fiscal y el lavado de dinero.

De tal forma que en la mayoría de los países el marco jurídico de dicha relación jurídica entre la administración pública tributaria y el contribuyente se sustente actualmente en dos cimientos: primero en el sistema del pago de las contribuciones en tiempo y en forma, requiriéndose para ello de deberes formales por parte del sujeto obligado; y por otra parte, la atribución de varias potestades de control por parte de la administración tributaria (Delgado, 2009), para realizar verificaciones o auditorías actualmente ya electrónicas al contar con documentos digitales que manifiestan las operaciones económicas realizados por los contribuyentes.

Sin embargo, si bien es cierto que la modernidad y el avance tecnológico contribuyen actualmente en la obtención de objetivos estratégicos empresariales; pero también se ha usado con el propósito del ocultamiento o apariencia legal de los medios para la obtención de los ingresos o bien para justificar diversas erogaciones simuladas y evitar así una base gravable mayor o real en la tributación; instrumentándose por ello, diversas herramientas jurídicas y diseño de procedimientos administrativos para indagar el uso u obtención del dinero, aplicando diversas sanciones por los actos ilegales (Vela, 2015).

Por lo tanto, es evidente entonces que el Estado para cumplir con su deber constitucional de suministrar a la sociedad de bienestar social mediante la ejecución del gasto público, las normas tributarias se basen en una política meramente recaudatoria; no obstante, para llevar dicha labor se 
ha visto en la imperiosa necesidad de implementar acciones complementarias que contribuyan con tal objetivo; las cuales no menoscaben el vínculo entre el Estado y los particulares, pero que a su vez coadyuven en soslayar el perjuicio del capital recaudatorio tributario, originado por prácticas ilegales ejercidas por los sujetos pasivos a efecto de contraer la carga impositiva a través de diversos actos fiscales contemplados como ilícitos, entre los cuales destacan la evasión y por ende la defraudación fiscal (León, 2018).

Precisamente a los actos ilícitos, Rodríguez (1995) comparte que el vocablo de "ilicitud", representa la contradicción del derecho, involucrando con ello la presencia de algo no permitido u opuesto a lo jurídico, presentándose en todas las áreas legales. Mientras que Ríos (2005) de manera más específica al caso que nos ocupa, sintetiza que el "ilícito tributario" es la transgresión de la normas jurídicas tributarias mediante hechos antijurídicos, verbigracia, la omisión de actos establecidos o en la realización de los prohibidos por la ley; consiguiendo ser retribuido con sanciones administrativas, penales o civiles en atención a la política legislativa del sistema jurídico en que se ubique la arbitrariedad.

Justamente al respecto, la evasión fiscal ha sido un problema que perjudica prácticamente a todas las economías del mundo, ocasionada por distintos factores y en medidas disímiles, sin embargo, lo que sí es congruente son los resultados nocivos sobre el crecimiento y desarrollo en las naciones (CEFP, 2019), en virtud que los gobiernos al dejar de percibir ingresos por tal circunstancia se encuentra en un escenario menos propicio para cumplir con sus funciones (Lara, 2007).

En este mismo orden y dirección, los primeros estudios en correlación a la evasión fiscal desde la perspectiva económica se originan con Allingham y Sandmo (1972), quienes argumentan que tal escenario surge en la década de los setenta y sintetizan que la evasión es la consecuencia de la decisión del sujeto que incrementa sus ganancias estimando los costos y beneficios que conlleva de evadir al fisco, así como los riesgos que ocasiona tal conducta (Daza, Sánzhez y Leaños, 2019).

En esta semejante tesitura, (Gamazo, 1994; Rodríguez, 2001; Ochoa, 2014; Sarduy, 2017 y Cárdenas, et al., 2019) armonizan y complementan en que la evasión fiscal se ha conceptualizado como el incumplimiento de pago de un impuesto, mediante la simulación o una serie de artificios, acciones u omisiones ilícitas, uso de medios diferentes e ilegales que pueden incluir el ocultamiento o el sobreponte de ingresos, la exageración de las erogaciones deducibles con adiciones ficticias, exenciones reducidas no permitidas por la norma jurídica al falsear su verdadero valor.

Es preciso señalar, que a pesar de los esfuerzos efectuados para restringir dicho fenómeno en el caso del Estado mexicano, aún existe un escenario con magnitud considerable en correlación al bajo nivel obtenido en términos del Producto Interno Bruto (PIB), ya que en atención al promedio de recaudación de los países miembros de la Organización para la Cooperación y el Desarrollo Económico (OCDE) durante el año 2017 se expresó en un 34.2\% (CEFP, 2019); mientras que en México dicha simetría en el mismo período de análisis efectuado se halló a la mitad según la base de datos global de estadísticas tributarias del organismo en mención al contar con un ratio de recaudación tributaria sobre PIB del 16.2\% (OCDE).

Ahora bien, otra complicación vinculada a la evasión que enfrentan los gobiernos, la simboliza el lavado de dinero. Desde el ámbito internacional, la Convención de Palermo emitida por la Organización de las Naciones Unidas en el año 2000 (ONU, 2004), se instituye en su artículo 6º que cada Estado parte de la misma, adoptará en atención a los principios fundamentales de su derecho doméstico, las medidas legislativas que sean ineludibles para tipificar como delito; cuando se cometan de manera intencional las acciones de: 1) convertir o transferir bienes, teniendo conocimiento que son productos del delito, o bien, con el objetivo de encubrir el origen ilegal de los mimos o auxiliar a cualquier individuo implicado en el cometido de eludir las secuelas jurídicas de 
sus actos; 2) la ocultación de la indudable naturaleza, la génesis, localización, movimiento o posesión de activos con conocimiento que se originan del delito. En ese mismo sentido (González, 2012 y Cárdenas, et al., 2019), comparten que es el proceso de ocultamiento de recursos provenientes de actividades ilícitas, los cuales son convertidos en actividades legítimas a través de la creación de empresas que simulan contar con una actividad preponderante, obteniendo así utilidades que pagarán contribuciones y en algunos casos usando estrategias para aún evadir el pago de las mismas al fisco federal.

Por lo tanto, mientras existan delitos que produzcan grandes utilidades para sus creadores, impulsa a los mismos de forma interpósita en muchos de los casos, dando un aspecto legal al origen del cual proceden las mismas ganancias; recurriendo así al lavado o blanqueo de capitales mediante la introducción de los recursos de procedencia ilícita al circuito económico legal (Coz, 1997).

Indiscutiblemente es un fenómeno complejo que para su aplicación se lleve a cabo implica la participación de un gran número de instituciones e individuos interesados que aprovechan en algunos de los casos la existencia de los paraísos fiscales, lagunas legales, la inexistencia de disposiciones jurídicas e instrumentos administrativos que pronostiquen sus peculiaridades, logrando hacer lícito lo que en su génesis no lo era (Núñez, 2008).

\subsection{La facultad de la presunción fiscal.}

Por lo anteriormente expuesto, pese a que la mayoría de los gobiernos cuenten con instituciones nacionales, apoyo con organismos internacionales, unidades de inteligencia financiera (UIF), la existencia de normas jurídicas que instituyan la obligatoriedad de contribuir al gasto público y de manera específica en contribuciones catalogadas como directas e indirectas, entre otros instrumentos para combatir la evasión fiscal, el lavado de dinero y por ende la defraudación fiscal en perjuicio de las finanzas públicas y por ende a la solventación del gasto público; han tenido que recurrir a la facultad de la presunción.

Con referencia a la presunción, la Real Academia Española (RAE) en su diccionario del español jurídico, la define como "aceptación de un hecho del que no se tiene prueba y que se infiere de otro hecho demostrado". En el ámbito del derecho fiscal, tanto la doctrina como la interpretación judicial y el poder legislativo, han reiterado y resaltado la implementación de las presunciones como uno de los instrumentos necesarios para impedir y/o combatir la evasión, el lavado de dinero y la defraudación fiscal, evaluando de esa manera la capacidad económica y capacidad contributiva de los contribuyentes o no causantes formalmente identificados, siendo considerada tal facultad como imprescindible (Venegas, 2007).

Si bien es cierto que la norma jurídica en la esfera tributaria es construida a través de la abstracción de hechos que se ubican en el ámbito del estado y de la actividad económica del contribuyente, siendo ambos capaces para revelar su capacidad contributiva; sin embargo, el hecho imponible se efectúa con los actos realizados por el causante sin que se produzca la intervención de la administración tributaria. No obstante, actualmente en la ejecución de la norma se hace necesario que dichos actos económicos o administrativos realizados por los sujetos sean del conocimiento de la misma administración para impedir que el tributo sea evadido. Por tal motivo, en los ordenamientos fiscales y procedimientos administrativos de las administraciones tributarias en la actualidad, las presunciones son una de las técnicas jurídicas fundamentales para la regulación de la prueba en el derecho tributario (Catureli, 2005).

Sobre la base de las consideraciones anteriores, en México se han efectuado una serie de análisis en correspondencia a la disquisición y aplicación de la legislación fiscal relacionada a la emisión de facturas electrónicas o Comprobantes Fiscales Digitales por Internet (CFDI's) y sus efectos 
jurídicos. Verbigracia, Encarnación, et al. (2018) comparten el contexto del acto ilícito sobre la enajenación de comprobantes fiscales que soportan operaciones inexistentes, con el objeto de disminuir la base gravable de los sujetos adquirentes de los mismos. Asimismo, Murcia, Vega y Sánchez (2019), concuerdan que tales prácticas han degradado las bases gravables de los sujetos pasivos, afectando con ello las finanzas públicas con un contexto adverso en la impartición de justicia y equidad; generándose de tal manera efectos fiscales nocivos por malas prácticas empresariales.

En esta misma tesitura, se han realizado algunos estudios a través de la interpretación doctrinal y en combinación con las distintas disquisiciones judiciales. A guisa de ejemplo, Roa (2021); entre sus diversas aportaciones, concluye que en atención al concepto de la "materialidad", se ha sostenido en la ejecución de ley su improcedencia, en virtud que tal vocablo no se contempla en la norma jurídica para tal efecto. Asimismo, a través de su interpretación desarrolla el concepto de "sustancia económica", lo cual ha sido utilizado por las autoridades hacendarias para acreditar la afectiva existencia de las operaciones. Al respecto, Palma (2021), sostiene que aunque los comprobantes fiscales tienen por objeto el confirmar un hecho u acto con implicaciones fiscales, aun cumpliendo los requisitos formales para su emisión y recepción, cuando carecen de sustancia económica o razón de negocios; es cuando la autoridad ejecuta su facultad de presunción de la inexistencia de las actividades que se indican en los mismos documentos digitales.

\section{PROCEDIMENTOS METODOLÓGICOS}

Para el desarrollo de la presente investigación se apoyó en una metodología de tipo documental, descriptiva y deductiva; mediante el estudio de documentos de carácter jurídico, legislación aplicable y legajos especializados en el tema de análisis e indagaciones disponibles sobre la materia.

El tema del presente estudio se ha abordado en otras investigaciones a través del mismo procedimiento metodológico, al abordarse de una manera descriptita e interpretativa de la legislación aplicable, así como la exégesis judicial al representar una temática controversial desde su adición en la norma fiscal de México como en la ejecución de la misma. De tal manera que se pueden apreciar estudios como el de la introducción al artículo 69-B del Código Fiscal de la Federación (Irigoyen, 2021). En esta misa postura, Sánchez (2021), comparte el análisis entorno a la materialidad y el procedimiento contenido en el mismo numeral de la norma tributaria antes citado.

De igual forma, Arteaga (2021), colabora su estudio sobre el desconocimiento del procedimiento de la razón de negocios de operaciones realizadas por contribuyentes sujetos al ejercicio de facultades de comprobación. Asimismo, sobresalen los trabajos sobre la materialidad de operaciones (Esquivel, 2021), la sustancia económica y razón de negocios como elementos para acreditar la autenticidad de una operación (Rodríguez, 2021). Con los mismos propósitos, se aprecian las elucidaciones sobre los conceptos jurídicos fundamentales (Niño, 2021), la seguridad jurídica y derecho de audiencia respecto al artículo 69-B del Código Fiscal de la Federación (Rivera, 2021); así como la óptica empresarial sobre la materialidad de los actos para los efectos fiscales (Gutiérrez, 2021).

Además de la interpretación jurídica, para el desarrollo del presente estudio, se utilizó la técnica de localización, fijación y tratamiento de datos estadísticos a través de la herramienta de Excel con cifras emitidas por el Servicio de Administración Tributaria (SAT) en su apartado denominado "datos abiertos", en sus variables específicas de "factura electrónica", "e-firma" y "contribuyentes publicados y acciones contra la delincuencia", exhibiendo su comportamiento con base en la estadística descriptiva. Con el objeto de soportar el análisis realizado a la interpretación jurídica del caso, la localización de datos se realizó en el portal del SAT en la sección de datos abiertos, seleccionando para el caso que no ocupa los siguientes rubros y variables disponibles. 
Tabla 1.Rubros y variables localizadas.

\begin{tabular}{|c|c|l|}
\hline Rubro & Variable & \multicolumn{1}{c|}{ Descripción } \\
\hline $\begin{array}{c}\text { Factura } \\
\text { electrónica }\end{array}$ & $\begin{array}{c}\text { Certificados de } \\
\text { e-firma }\end{array}$ & $\begin{array}{l}\text { Certificados e-firma emitidos por primera ocasión al } \\
\text { contribuyente, para efectuar distintos trámites digitales } \\
\text { ante las autoridades fiscales conforme a la legislación } \\
\text { tributaria en México. }\end{array}$ \\
\hline $\begin{array}{c}\text { Factura } \\
\text { electrónica }\end{array}$ & $\begin{array}{c}\text { Certificados de } \\
\text { e-firma y CSD }\end{array}$ & $\begin{array}{l}\text { Certificados e-firma y CSD emitidos a los contribuyentes, } \\
\text { para efectuar distintos trámites digitales ante las } \\
\text { autoridades fiscales conforme a la legislación tributaria } \\
\text { incluyendo la emisión de comprobantes fiscales. }\end{array}$ \\
\hline $\begin{array}{c}\text { Factura } \\
\text { electrónica }\end{array}$ & $\begin{array}{c}\text { Número de } \\
\text { comprobantes }\end{array}$ & $\begin{array}{l}\text { Cantidad de CFDI's emitidos por contribuyentes en } \\
\text { México }\end{array}$ \\
\hline $\begin{array}{c}\text { Contribuyentes } \\
\text { publicados y } \\
\text { acciones contra la } \\
\text { delincuencia }\end{array}$ & $\begin{array}{c}\text { completo de } \\
\text { contribuyentes } \\
\text { (Artículo 69-B } \\
\text { del CFF) }\end{array}$ & $\begin{array}{l}\text { LFF) publicados en el Diario Oficial de la Federación, en } \\
\text { situación fiscal de definitivos, presuntos, sentencia } \\
\text { favorable y desvirtuado. }\end{array}$ \\
\hline
\end{tabular}

Fuente: Elaboración propia con datos expuestos por el SAT.

\section{RESULTADOS Y DISCUSIÓN.}

\subsection{Medios electrónicos en la fiscalización}

Aunado a lo anteriormente expuesto, aun existiendo la fundamentación constitucional y en normas jurídicas domésticas implementadas en México la obligatoriedad de contribuir al gasto público, en las últimos años el gobierno ha apelado a distintas estrategias para evitar la informalidad e incrementar la base de los contribuyentes, así como acciones en búsqueda de soslayar la evasión fiscal y el lavado de dinero, representando estos últimos los principales problemas que enfrenta la administración tributaria.

Es preciso señalar que tales acciones no han sido exclusivas del Estado mexicano, en virtud que en países de América Latina y España han efectuado un conjunto de derechos y deberes administrativos de colaboración de parte del contribuyente en otorgar información económica con importancia fiscal a la administración (Ríos, 2006); implementándose para ello el uso de las TIC's, donde en el caso de los contribuyentes en México, desde la comodidad de su hogar o trabajo pueden efectuar diversos trámites para el cumplimiento de sus obligaciones fiscales a través del internet en el portal del SAT (Ríos, 2003).

Dichas acciones han consistido en el establecimiento de cargas de índole administrativa hacia los contribuyentes para efectos del cumplimiento de sus obligaciones en materia fiscal, realizándose una serie de reformas en el Código Fiscal de la Federación (CFF), obteniendo un nuevo paradigma de la tributación en México y contando en sus inicios con su entrada en vigor el primero de enero del 2004 con algunas modificaciones en los ejercicios fiscales posteriores, destacando la emisión de comprobantes digitales por medios electrónicos o facturas electrónicas y denominándose en la actualidad como CFDI's, la implementación de la Firma Electrónica Avanzada, instrumento que ha variado en su acrónimo desde sus inicios a la fecha como (FEA, FIEL y e-firma) (Osorio, 2017) misma que a partir del 11 de enero del 2012 cuenta con su norma jurídica que reglamenta su uso y validez, legislación intitulada como Ley de Firma Electrónica Avanzada (LFEA), así como el empleo del medio de contacto electrónico entre el SAT y el contribuyente denominado Buzón Tributario (BT), la gestión de sellos digitales para la emisión de comprobantes, entre otras modificaciones al ordenamiento jurídico citado.

En relación a la e-firma, se establece en el artículo 17-D del CFF que las disposiciones fiscales podrán requerir documentos digitales, utilizándose para ello el uso de dicha firma electrónica, la 
cual se gestiona por parte del contribuyente ante el SAT y que dispone con una vigencia de 4 años, la cual cuenta con un certificado que confirma el vínculo entre el firmante y los datos de creación; sustituyéndose en los documentos la firma autógrafa, garantizándose la probidad del documento y que causará los mismo efectos legales al tener el mismo valor probatorio. Precisamente al respecto, en atención a los datos expresados por el SAT, en el período enero del 2004 al mes de agosto del 2021 se han emitido más de 17 millones de certificados de la e-firma a los contribuyentes que han solicitado su trámite ante dicha dependencia gubernamental por primera ocasión, de los cuales el $90 \%$ y $10 \%$ corresponden a personas físicas $(\mathrm{PF})$ y personas morales $(\mathrm{PM})$ respectivamente.

Tabla 2. Certificados de e-firma emitidos por primera ocasión al contribuyente en México. Enero 2004 al mes de agosto 2021.

\begin{tabular}{rrrr} 
AÑ & \multicolumn{1}{c}{ PF } & \multicolumn{1}{c}{ PM } & \multicolumn{1}{c}{ TOTAL } \\
2004 & 42266 & 21633 & 65903 \\
2005 & 264940 & 139062 & 406007 \\
2006 & 354444 & 66298 & 422748 \\
2007 & 325908 & 82798 & 410713 \\
2008 & 237086 & 49995 & 289089 \\
2009 & 307916 & 136361 & 446286 \\
2010 & 599431 & 98428 & 699869 \\
2011 & 1153482 & 140367 & 1295860 \\
2012 & 1278027 & 134788 & 1414827 \\
2013 & 1007419 & 120738 & 1130170 \\
2014 & 1211483 & 112734 & 1326231 \\
2015 & 956803 & 102160 & 1060978 \\
2016 & 1174711 & 105204 & 1281931 \\
2017 & 1429580 & 104453 & 1536050 \\
2018 & 1369687 & 104978 & 1476683 \\
2019 & 1781936 & 107762 & 1891717 \\
2020 & 1182870 & 72856 & 1257746 \\
2021 & 889956 & 58358 & 950335 \\
\hline Acumulado & $\mathbf{1 5 5 6 7 9 4 5}$ & $\mathbf{1 7 5 8 9 7 3}$ & $\mathbf{1 7 3 6 3 1 4 3}$
\end{tabular}

Fuente: Elaboración propia con datos expuestos por el SAT.

De igual manera, tomando en cuenta el régimen en el cual tributa el contribuyente, en la mayoría de las modalidades de tributación se necesita gestionar un Certificado de Sello Digital (CSD) para estar en la posibilidad de emitir sus CFDI's hacia sus clientes por la enajenación de bienes, productos o por la prestación de servicios según sea el caso, así como los recibos de nómina que también se deben de timbrar como cualquier comprobante fiscal; requiriéndose contar con e-firma actualizada, lo cual conlleva a que un contribuyente además de necesitar el certificado de la firma digital, puede requerir de certificados especiales para la facturación por sus ingresos. De tal manera que, según cifras del SAT en el mismo período de enero del 2004 al mes de agosto del 2021, se han emitido más de 31.5 millones de archivos digitales de autenticidad de sujetos obligados, de los cuales el $86 \%$ y $14 \%$ correspondieron a personas físicas y morales respectivamente.

Tabla 3. Certificados de e-firma y CSD emitidos al contribuyente en México.

\begin{tabular}{|rrrr|}
\multicolumn{4}{c}{ Enero 2004 al mes de agosto 2021. } \\
AÑ & \multicolumn{1}{c}{ PF } & \multicolumn{1}{c|}{ PM } & TOTAL \\
2004 & 42282 & 21642 & 63924 \\
2005 & 269431 & 145434 & 414865 \\
2006 & 371628 & 77843 & 449471
\end{tabular}




$\begin{array}{crrr}2007 & 467328 & 193740 & 661068 \\ 2008 & 428907 & 112201 & 541108 \\ 2009 & 670778 & 311781 & 982559 \\ 2010 & 1025099 & 223106 & 1248205 \\ 2011 & 1777723 & 383280 & 2161003 \\ 2012 & 1991800 & 284735 & 2276535 \\ 2013 & 1497077 & 417675 & 1914752 \\ 2014 & 1806801 & 270499 & 2077300 \\ 2015 & 1815018 & 177994 & 1993012 \\ 2016 & 2407903 & 316712 & 2724615 \\ 2017 & 2476589 & 397006 & 2873595 \\ 2018 & 2703242 & 319581 & 3022823 \\ 2019 & 3133949 & 276000 & 3409949 \\ 2020 & 2347691 & 296323 & 2644014 \\ 2021 & 1852943 & 287916 & 2140859 \\ \text { Acumulado } & \mathbf{2 7 0 8 6 1 8 9} & \mathbf{4 5 1 3 4 6 8} & \mathbf{3 1 5 9 9 6 5 7}\end{array}$

Fuente: Elaboración propia con datos expuestos por el SAT.

De tal forma que los contribuyentes que han obtenido los certificados para e-firma y/o para CSD, con dichos instrumentos con información de autentificación encriptada, además de realizar distintos trámites en línea ante el SAT para efectos del cumplimiento de sus obligaciones fiscales los sujetos pasivos, también han estado en la posibilidad de emitir CFDI's por sus actividades económicas preponderantes registradas ante el Registro Federal de Contribuyentes (RFC), por lo que según el análisis realizado por el período del mes de enero 2005 al mes de noviembre del 2021, se han emitido de parte de los sujetos pasivos por encima de 63 mil millones de documentos digitales en los que manifiestan sus operaciones mercantiles por la venta de productos o servicios, generándose según las cifras al cierre del mes de noviembre del 2021, 273 comprobantes por segundo.

Gráfica 1. Cantidad de CFDI's emitidos por contribuyentes en México. Enero 2005 al mes de noviembre del 2021.

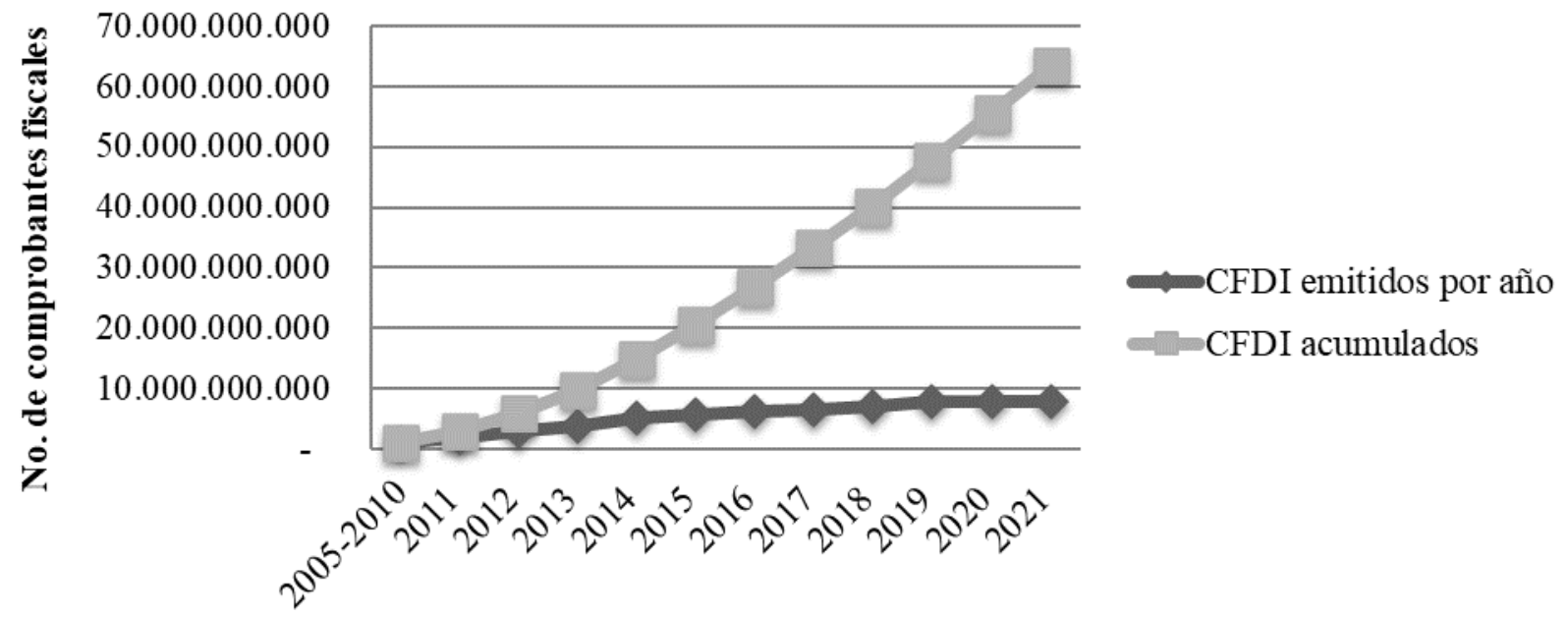

Fuente: Elaboración propia con datos expuestos por el SAT.

Es preciso señalar que, para efectos de la emisión de los CFDI's el contribuyente cuenta con la opción de elaborar dichos comprobantes fiscales a través del portal del SAT de manera gratuita, quien pone a disposición del sujeto obligado la herramienta de facturación electrónica y el portal de mis cuentas atendiendo a las características del régimen en que se encuentra tributando conforme a 
la legislación correspondiente. De igual forma, en atención al artículo 29 fracción IV del CFF, puede optar por expedir los CFDI's a través de un proveedor autorizado por el órgano desconcentrado de la Secretaría de Hacienda y Crédito Público (SHCP), para que efectúen la validación, asignación de folio e incorporación del sello; contando en la actualidad con 75 empresas como proveedores autorizados por el SAT y que prestan dicho servicio.

\subsection{La materialidad de las operaciones económicas}

Aunado a lo ya establecido con anterioridad, a finales del ejercicio fiscal del 2013, se efectuaron modificaciones relevantes a distintos ordenamientos fiscales en México, sobresaliendo la Ley del Impuesto Sobre la Renta (LISR), la Ley del Impuesto al Valor Agregado (LIVA) la Ley del Impuesto Especial Sobre Producción y Servicios (LIPES) y al CFF, reformas impulsadas por el titular del Ejecutivo Federal en dicho período, resaltando la adición del artículo 69-B del último instrumento jurídico fiscal referido.

A modo de preámbulo, el numeral del ordenamiento antes sobredicho se ubica en su apartado intitulado "Título Tercero" y mismo que refiere a las "Facultades de las Autoridades Fiscales", "Capítulo I". Dicha sección que se compone del artículo 33 al 69-B Ter; instituye aspectos relacionados con la asistencia gratuita hacia los sujetos obligados de parte de la autoridad para el cumplimiento de sus obligaciones fiscales, el establecimiento de los programas de prevención y resolución de problemas del contribuyente, lo referente al RFC y a la Clave Única de Registro de Población (CURP) para la identificación de los mismos, lo relacionado a las consultas efectuadas de parte de las personas físicas y morales, lo que atañe a las resoluciones administrativas, los requisitos para la notificación de los actos administrativos, lo vinculado con la facultad de la condonación contribuciones y accesorios, lo concerniente al aseguramiento o embargo de bienes precautoriamente, la facultad de practicar la visitas domiciliarias, entre otras varias potestades y procedimientos de parte de la autoridad fiscal; sobresaliendo lo tocante a la "presunción" de distintos actos, procedimientos o hechos realizados por el sujeto pasivo, atribución que en los últimos años ha generado grandes controversias en los tribunales en materia administrativa y penal.

Los numerales 69 y 69-A del CFF, refieren entre otros aspectos a que el personal de la dependencia del SAT deberá de guardar absoluta reserva en lo concerniente a las declaraciones y datos del contribuyente y lo relativo a la asistencia de cobro de contribuciones exigibles por los Estados extranjeros respectivamente; adicionándose a través de la reforma fiscal publicada en el Diario Oficial de la Federación (DOF) el 9 de diciembre del 2013, misma que entró en vigor el 01 de enero del 2014.

Atendiendo a la exposición de motivos de la reforma fiscal de aditamento del artículo 69-B del CFF, emitida por el Ejecutivo Federal, manifiesta que la circunstancia de su inclusión es el uso indebido de los comprobantes fiscales, al sostener que uno de las razones más perjudiciales y que mayormente han contribuido en lesionar la recaudación fiscal, son los esquemas agresivos de evasión fiscal, por lo que deben de eliminarse o amonestar los motivos que lo originan, mediante instrumentos eficaces que coadyuven combatirlos.

Durante mucho tiempo se aplicó indebidamente la práctica de utilizar comprobantes apócrifos con el objeto de deducirlos y acreditar las contribuciones manifestadas en los mismos, implementándose para ello de parte de las autoridades fiscales una serie de controles de seguridad. Sin embargo, dichas prácticas evolucionaron de tal forma que los causantes recurrieron a estrategias ilegales más complejas para la obtención de beneficios fiscales en detrimento del fiscal federal; verbigracia, el tráfico de comprobantes fiscales colocados en un mercado de facturas auténticas y con la contraprestación económica asequibles mediante transferencias bancarias o cheques nominativos, empero, careciendo de sustancia económica o razón de negocios en sus conceptos manifestados que 
aparentemente soportaban la erogación o el ingreso; identificando así el SAT una serie de estándares de comportamiento empresarial en aquellos que realizaron tales actos ilícitos (Exposición de motivos, en DOF del 9 de diciembre del 2013, p. CV-CVII) y que a la letra señala:

1. Tienen un objeto social muy amplio para poder ofrecer al cliente un comprobante fiscal con un concepto que pueda disfrazarse mejor dentro de las actividades preponderantes de éste.

2. Emiten comprobantes fiscales correspondientes a operaciones que no se realizaron.

3. Emiten comprobantes fiscales cuya contraprestación realmente pagada por las operaciones consignadas en los mismos es sólo un mínimo porcentaje y no tiene proporción con dichas operaciones.

4. No tienen personal o éste no es idóneo o suficiente para llevar a cabo las operaciones que se especifican en los comprobantes fiscales.

5. No tienen activos o éstos no son idóneos o suficientes para llevar a cabo las operaciones que se especifican en los comprobantes fiscales.

6. Reciben ingresos que no tienen proporción a las características de su establecimiento.

7. Tienen cuentas bancarias o de inversiones que se encuentran activas durante un periodo determinado y después son canceladas o las dejan con saldos infimos después de haber manejado cantidades elevadas.

8. Tienen sus establecimientos en domicilios que no corresponden al manifestado ante el registro federal de contribuyentes.

9. Sus sociedades se encuentran activas durante un período y luego se vuelven no localizables.

10. Sus ingresos en el ejercicio de que se trate son casi idénticos a sus deducciones o bien, éstas son mayores por escaso margen.

11. Prestan servicios y a la vez reciben servicios por casi exactamente los mismos montos.

12. Comparten domicilios con otros contribuyentes también prestadores de servicios.

Derivado de lo anteriormente sustentado y expuesto por parte de la autoridad administrativa en México, a través de dicha reforma legislativa en materia fiscal se adiciona el artículo 69-B del CFF, numeral que tuvo posteriormente algunas modificaciones y mismo que a la letra señala en su primer párrafo:

Artículo 69-B. "Cuando la autoridad fiscal detecte que un contribuyente ha estado emitiendo comprobantes sin contar con los activos, personal, infraestructura o capacidad material, directa o indirectamente, para prestar los servicios o producir, comercializar o entregar los bienes que amparan tales comprobantes, o bien, que dichos contribuyentes se encuentren no localizados, se presumirá la inexistencia de las operaciones amparadas en tales comprobantes".

Como se puede observar en el numeral antes citado, la autoridad fiscal a través de las facultades de comprobación al contar con los CFDI's emitidos y recibidos de los contribuyentes en sus sistemas de cómputo mediante las revisiones electrónicas, así como a través de visitas domiciliarias del personal a su cargo; al detectar que no se cuenta con los activos, personal, infraestructura, para la prestación de los servicios, producir o comercializar en atención al objeto social o actividad preponderante de la entidad económica, lo cual debe de ser congruente con lo manifestado en los comprobantes fiscales o bien, en caso de que no se encuentre localizado en el domicilio registrado ante el RFC inferirá la no existencia de las operaciones manifestadas en los documentos digitalizados por los causantes, entendidos en la práctica fiscal como Empresas que Facturan Operaciones Simuladas (EFOS).

Atendiendo al segundo párrafo del numeral en estudio, instituye que en caso de estar dicho supuesto, se procederá a notificar a los contribuyentes a través de la herramienta del BT en la página del SAT, así como mediante la publicación de la denominación de las razones sociales en caso de personas morales o bien el nombre para las personas físicas en el DOF, a fin de que en un plazo de quince días partir de la última notificación puedan exhibir ante las autoridades lo que a su derecho convenga y exponer la documentación e información que estimen oportunos para desvirtuar 
los hechos que provocó a la autoridad notificarlos o exhibirlos en el instrumento oficial del gobierno federal.

Es preciso señalar que los párrafos siguientes del artículo en análisis, instituyen la opción de solicitar una prórroga por única ocasión de cinco días al plazo ya previsto para exhibir la documentación e información respectiva, contando la autoridad en un plazo no mayor a cincuenta días para valorar y notificar la resolución mediante el BT a los contribuyentes; aclarando que, se publicará un listado en el DOF y en el portal del SAT de los sujetos pasivos que no hayan desvirtuado los hechos que se le imputaron, encontrándose en tal caso en el status de "definitivo" en el hecho que se instituye en el primer párrafo de artículo 69-B del CFF.

De igual manera, se establece que a través de los mismos medios de comunicación antes referidos, la autoridad publicará trimestralmente el listado de los contribuyentes que lograron comprobar a su favor, así como aquellos que obtuvieron resolución o sentencia firme derivado de los medios de defensa presentados por los causantes, tipificándolos en tales casos con el status de "desvirtuado" y "sentencia favorable" respectivamente.

Asimismo, se aclara que las personas físicas y morales que hayan dado cualquier efecto fiscal como la deducibilidad o acreditamiento de las contribuciones de los CFDI emitidos por contribuyentes catalogados como EFOS e incluidos en las listas con status de definitivos, dichos contribuyentes también estarán en el programa de fiscalización siendo catalogadas en la práctica fiscal como Empresas que Deducen Operaciones Simuladas (EDOS); siendo sujetos así a un procedimiento que les concede la opción de autocorrección fiscal, es decir, corregir su contabilidad y efectuar declaraciones de impuestos complementarias, o bien, se les impone el deber jurídico para acreditar la efectiva realización de las operaciones en los comprobantes expedidos por los EFOS.

En caso de que tanto EFOS como EDOS no acrediten la debida prestación del servicio o enajenación de productos o bien, no hayan realizado la corrección fiscal respectivamente, se les determinará los créditos fiscales que correspondan conforme al mismo CFF.

Figura 1. Exégesis sistemática de la integración del artículo 69-B del CFF

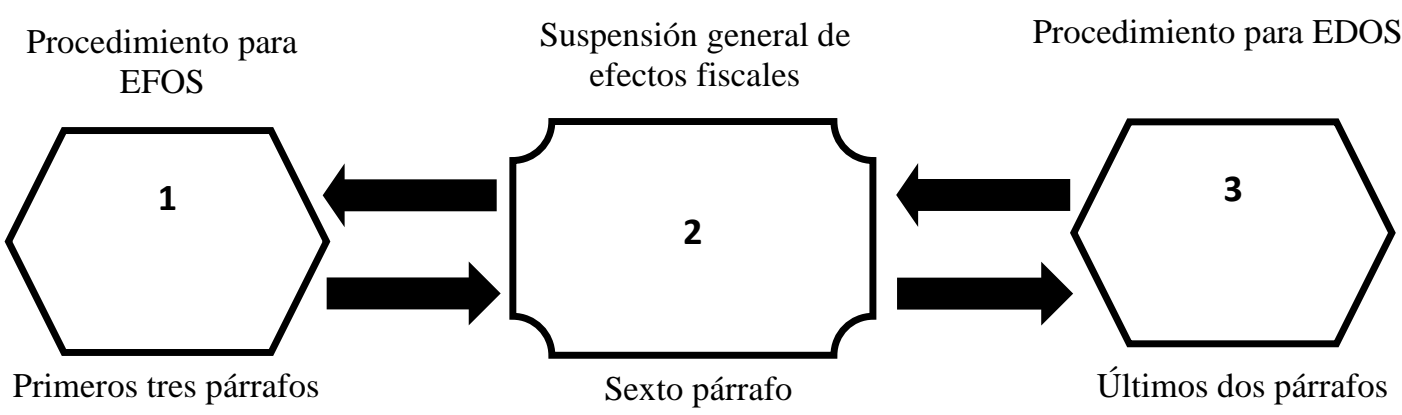

Fuente: Elaboración propia con información en Mendoza (2015).

Tal es el caso que de acuerdo a la información expuesta por el SAT al mes de agosto del 2021, se han publicado en el DOF y portal del SAT un total de 12627 contribuyentes, de los cuales en atención al análisis realizado cerca del $79 \%$ corresponde a Personas No Físicas (PNF), casi el $21 \%$ a Personas Físicas (PF), mientras que por debajo del $1 \%$ clasificados con información suprimida en cumplimiento a declaratoria de nulidad emitida por alguna sala del Tribunal Federal de Justicia Fiscal y Administrativa (TFJFA), clasificándolos para el caso que nos atañe como (SUP). Las PNF manifestadas en el listado del DOF y en la página de internet del SAT, para efectos del presente estudio, se han catalogado en Personas Morales (PM), Cámaras, Sindicatos y Ejidos; sobresaliendo la primer clasificación en más del 99\%, en relación al total de dicha relación. 
Tabla 4. PNF presentados en el listado en el DOF y en el portal del SAT en correlación al artículo 69-B del CFF, al mes de agosto del 2021.

\begin{tabular}{lrr}
\multicolumn{1}{c}{ Tipo de PNF } & Publicados & \multicolumn{1}{c}{$\%$} \\
\hline PM & 9912 & $99.81 \%$ \\
Cámaras & 4 & $0.04 \%$ \\
Sindicatos & 14 & $0.14 \%$ \\
Ejidos & 1 & $0.01 \%$ \\
\hline \multicolumn{1}{c}{ Total } & 9931 & $100.00 \%$
\end{tabular}

Fuente: Elaboración propia con datos expuestos por el SAT.

Ahora bien, limitándonos al caso de las PM, se detecta en el análisis realizado todo tipo de modalidades de conformación sociedades mercantiles conforme a la Ley General de Sociedades Mercantiles (LGSM), destacando en primer término la Sociedad Anónima de Capital Variable (S.A. de C.V.), la Sociedad de Responsabilidad Limitada (S. de R.L.), la Sociedad de Responsabilidad Limitada de Capital Variable (S de R.L. de C.V.), Sociedad Cooperativa (S.C.). Dichas modalidades de razón social son las que mostraron mayor número en el listado.

Tabla 5. Tipo de PM enlistadas en el DOF y en el portal del SAT en correlación al artículo 69-B del CFF, al mes de agosto del 2021.

\begin{tabular}{lrr} 
Tipo de sociedad & Publicados & \multicolumn{1}{c}{$\%$} \\
S.A. de C.V. & 8000 & $80.71 \%$ \\
S.C. & 822 & $8.29 \%$ \\
S. de R.L. & 753 & $7.60 \%$ \\
Otras & 337 & $3.40 \%$ \\
\multicolumn{1}{r}{$\quad$ Total } & $\mathbf{9 9 1 2}$ & $\mathbf{1 0 0 . 0 0 \%}$
\end{tabular}

Fuente: Elaboración propia con datos expuestos por el SAT

Complementando el análisis efectuado, es de sorprender que de la población total de contribuyentes notificados por BT y enlistados en el DOF como en el portal del SAT al mes de agosto del 2021, cerca del $85 \%$ se encuentran en el status de "definitivos", es decir, no desvirtuaron los hechos que se les imputaron, ya sea mediante la exhibición de pruebas o bien, no interpusieron algún medio de defensa y en caso de haberlo gestionado ante la autoridad, resultó no favorable para el sujeto pasivo.

Asimismo, solamente $2.4 \%$ desvirtúo lo que la autoridad a través de su facultad de presunción detectó en sus CFDI emitidos, mientras que, el $7.7 \%$ obtuvo una sentencia favorable y el $5.1 \%$ se encontraron como presuntos a la fecha del análisis realizado, quienes deberán de desvirtuar ya sea mediante la exhibición de pruebas que sustenten la materialidad de las operaciones económicas manifestadas en sus CFDI o bien interpongan algún medio de defensa fiscal.

Gráfica 2. Situación fiscal de los contribuyentes enlistados conforme al artículo 69-B del CFF, al mes de agosto 2021. 


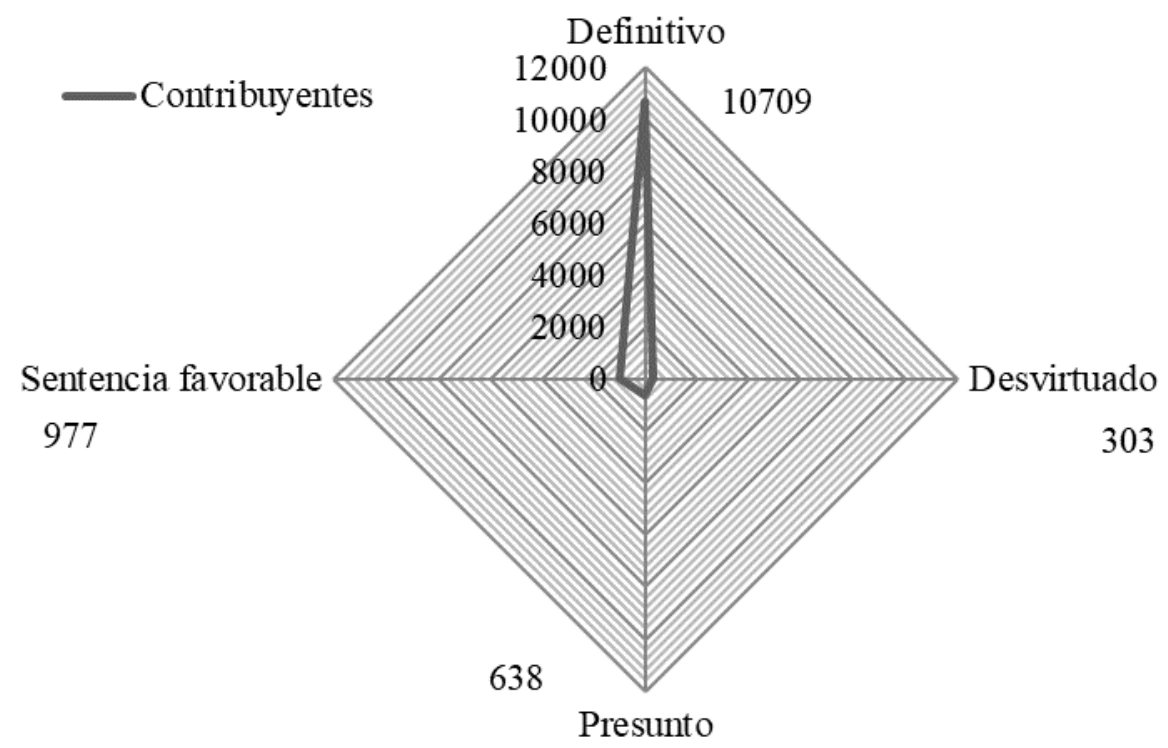

Fuente: Elaboración propia con datos expuestos por el SAT.

Ahora bien, examinando más detalladamente los porcentajes referidos con anterioridad, se exhibe en el análisis realizado el comportamiento estadístico de la situación fiscal por tipo de contribuyente, sobresaliendo en términos cuantificables el caso de las personas no físicas enlistadas en el DOF y portal del SAT, conforme al artículo 69-B del CFF.

\section{Gráfica 3. Situación fiscal por tipo de contribuyente en el listado conforme al artículo 69-B del CFF, al mes de agosto 2021.}

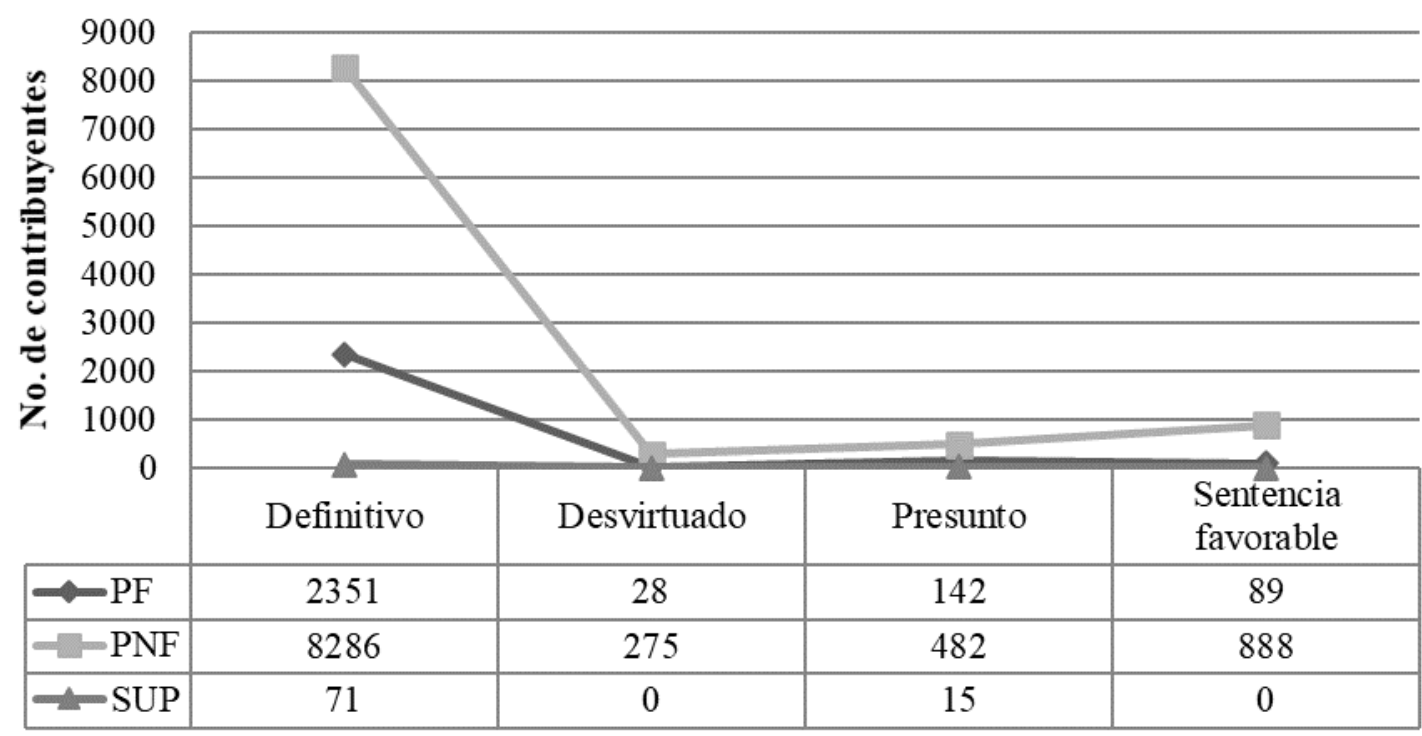

Fuente: Elaboración propia con datos expuestos por el SAT.

Indiscutiblemente que, para las organizaciones empresariales tanto aquellos que pueden catalogarse como EFOS o bien en situación como EDOS, es de vital importancia instaurar controles adecuadamente maduros, que les coadyuven en soslayar encontrarse en un escenario de este tipo, ya que podría ocasionarles efectos nocivos a su empresa, tales como la cancelación de sellos digitales al ser una de las facultades que dispone la autoridad y afectando de esa manera sus flujos de efectivo al impedírseles la emisión de sus CFDI's por sus actividades y por ende la no remuneración 
económica por las mismas, así como el posible congelamiento de sus cuentas bancarias e incluso tipificarse como delito con posibles consecuencias en el ámbito penal.

Por tal motivo, la materialidad de las operaciones económicas para efectos fiscales en México, ha conllevado que las administraciones de las empresas deban establecer medidas preventivas orientadas e incluso a la misma fiscalización de sus proveedores, entre las que destacan:

a) $\mathrm{Al}$ incluir a sus proveedores en la cadena de valor es recomendable analizar las circunstancias comerciales que permitan identificar riesgos relacionados con su solvencia moral.

b) Inspeccionar constantemente las listas en el DOF o página del SAT de contribuyentes que se encuentren en el status de presuntos o definitivos por sus operaciones inexistentes.

c) Analizar de manera escrupulosa el cumplimiento de la materialidad de las condiciones celebradas entre las partes en los contratos, verbigracia, sub arrendamientos, subcontratación u outsorucing, entre otras.

d) Administrar un expediente que integre todos los elementos documentales impresos y/o digitales emitidos por sus proveedores que permitan soportar de manera eficiente la existencia de operaciones económicas reales.

e) Cerciorarse que sus proveedores dispongan de activos, infraestructura, recursos humanos y sobre todo capacidad económica. (Arellano, 2017).

\section{CONCLUSIÓN}

A modo de conclusión, queda muy claro que el Estado al convertirse en un ente económico demanda de recursos pecuniarios para su funcionamiento y cumplimiento de la solventación del gasto público, instituyéndose para ello su potestad irrenunciable desde la Ley suprema en el caso mexicano, así como en ordenamientos jurídicos que establecen la obligatoriedad de tener que contribuir al gasto público mediante impuestos directos e indirectos que gravan las utilidades, el ingreso, el patrimonio o el consumo.

En esta misma tesitura, queda clara la importancia que imperan los impuestos en México al representar la principal fuente de financiamiento del gasto público, destacando los casos del ISR, el IVA e IEPS; contribuciones que han contado en los últimos años con reformas estructurales en sus elementos esenciales del tributo en concordancia con el CFF, el cual es el eje rector de las normas fiscales en México. Precisamente al respecto del último ordenamiento jurídico expuesto, se demuestra que el Estado mexicano ha estado implementando acciones orientadas a disminuir la informalidad, incrementar la base de contribuyentes, pero sobre todo la ejecución de estrategias jurídicas para combatir la evasión fiscal, el lavado de dinero y la defraudación fiscal apoyándose en la implementación de las TIC's en la administración tributaria, mediante el uso la e-firma, CFDI's, la Contabilidad Electrónica, el BT, entre otros instrumentos que han cambiado el paradigma de la tributación en México, al ampliarse además sus facultades de presunción en los actos realizados por los contribuyentes.

Indiscutiblemente, las argumentaciones manifestadas en la exposición de motivos de la reforma del artículo 69-B del CFF han sido más que válidas, tomando en consideración que son argumentos de sustancia económica y razón de negocios, donde además los resultados obtenidos al período de estudio de parte de la autoridad fiscal muestran un porcentaje muy alto de empresas en condiciones de "definitivos" catalogándose de tal manera como EFOS y que tendrán sus consecuencias jurídicas por tales actos, así como sus efectos fiscales y posibles consecuencias para aquellos entes económicos que hayan realizado operaciones con las mismas al encontrarse en un escenario como EDOS. 
Por lo tanto, vale la pena reflexionar el escenario del nuevo paradigma fiscal que enfrentan las empresas en México para el cumplimiento de sus obligaciones tributarias, con nuevas cargas administrativas y el asumir acciones para prevenir problemas futuros tanto en la emisión como en la recepción del CFDI's con el soporte de la materialidad de la operaciones económicas para que no sean consideradas como inexistentes.

Es preciso señalar que una de las limitaciones en el proceso de estudio, lo refleja la dificultad de la obtención de los datos económicos con afectación a las finanzas públicas y/o al sector empresarial por la emisión de CFDI's que no soportan la materialidad de las operaciones económicas o bien que así se ha presumido por parte de la autoridad fiscal. Por la motivo, sirva el presente análisis para futuros estudios teóricos o experimentales en correspondencia a la exégesis y aplicación jurídica del artículo 69-B del Código Fiscal de la Federación en México.

\section{REFERENCIAS}

Allingham, M. \& Sandmo A. (1972). Income Tax Evasion: a Theoretical Analysis. Journal Publics Economics, vol. 1 323-338. [En línea]. Disponible en: http://www3.nccu.edu.tw/ klueng/tax\%20paper/1.pdf [Extraído el 20 de noviembre del 2021].

Arellano, (2017). El impacto de las Operaciones Inexistentes. Práctica Fiscal, No. 833, pp. 21 -24. [En línea]. Disponible en: https://doctrina.vlex.com.mx/vid/impacto-operaciones-inexistentes-702448157 [Extraído el 18 de noviembre del 2021].

Arteaga, R., (2021). El procedimiento de desconocimiento de la razón de negocios de operaciones realizadas por contribuyentes sujetos al ejercicio de facultades de comprobación. Revista de la Procuraduría Fiscal de la Federación. Enero-junio, Año 1 No. 2, pp. 153-176. [En línea]. Disponible en: https://www.gob.mx/shcp/pff/cee/documentos/revista-de-la-procuraduria-fiscal-de-la-federacion-ano-1-no-2263517 [Extraído el 9 de enero 2022].

Cárdenas, et al, (2019). Diccionario de Auditoría: Informes, dictámenes y términos español e inglés. $1^{\text {a }}$ ed. Universidad de Guadalajara, Centro Universitario de Ciencias Económico Administrativas, México.

Carrasco, H. (2017). Derecho Fiscal I. IURE editores, Ciudad de México.

Catureli, E. (2005). Presunciones en el Derecho Tributario. En Temas Actuales del Derecho Tributario, González y Vilar (Coord.). JM BOSCH EDITOR, Barcelona, España.

CEFP (2019). El Pago de Impuestos y la Evasión Fiscal en México. Cámara de Diputados LXIV Legislatura. [En línea]. Disponible en: https://www.cefp.gob.mx/publicaciones/documento/2019/cefp0132019.pdf [Extraído el 22 de noviembre del 2021].

Código Fiscal de la Federación. Publicado en el Diario Oficial de la Federación el 31 de diciembre de 1981. Última reforma publicada el 12 de noviembre 2021. [En línea]. Disponible en:

https://www.diputados.gob.mx/LeyesBiblio/pdf/CFF.pdf [Extraído el 18 de noviembre del 2021].

Constitución Política de los Estados Unidos Mexicanos. Publicada en el Diario Oficial de la Federación el 5 de febrero de 1917. Última reforma publicada en el Diario Oficial de la Federación el 28 de mayo del 2021. [En línea]. Disponible en: https://www.diputados.gob.mx/LeyesBiblio/pdf/CPEUM.pdf [Extraído el 18 de noviembre del 2021].

Coz, E. (1997). Transacciones Sospechosas y el Delito de Lavado de Dinero. THĒMIS-Revista de Derecho, núm. 35, pp. 81-85. [En línea]. Disponible en: http://revistas.pucp.edu.pe/index.php/themis/article/view/11760/12332 [Extraído el 24 de noviembre del 2021].

Daza, M., Sánchez, A. \& Leaños, S. (2019). Ética de lo Fiscal y su Aplicación Práctica. 1ª ed., Dofiscal Editores, México, Ciudad de México.

Delgado, A. (2009). Administración Electrónica Tributaria. JM BOSCH EDITOR, Barcelona. [En línea]. Disponible en: https://elibro.net/es/ereader/ues/52307 [Consultado el 22 de noviembre 2021]. 
DOF. DECRETO por el que se reforman, adicionan y derogan diversas disposiciones del Código Fiscal de la Federación. [En línea]. Disponible en: http://www.dof.gob.mx/nota_detalle.php?codigo=5324942\&fecha=09/12/2013 [Extraído el 18 de noviembre del 2021].

DOF. Exposición de motivos, proceso legislativo. DECRETO por el que se reforman, adicionan y derogan diversas disposiciones del Código Fiscal de la Federación, en el Diario Oficial de la Federación del 9 de diciembre del 2013. [En línea]. Disponible en: http://www.diputados.gob.mx/sedia/biblio/prog_leg/103_DOF_09dic13.pdf [Extraído el 18 de noviembre del 2021].

Dorantes, L., \& Gómez, M. (2014). Derecho Fiscal. Grupo Editorial Patria, México, .D.F. Dykinson, Madrid.

Encarnación, S., et al., (2018). Los Comprobantes Fiscales y las Operaciones Inexistentes del Artículo 69-B, del Código Fiscal de la Federación. Memorias del Congreso Internacional de Investigación. Academia Journals. Vol. 10, No. 3, pp. 1009-1014. [En línea]. Disponible en: http://ri.uagro.mx/bitstream/handle/uagro/1124/ART_16261204-.pdf?sequence=1\&isAllowed=y [Extraído el 9 de enero 2022].

Esquivel, G., (2021). De la materialidad de las operaciones. Revista de la Procuraduría Fiscal de la Federación. Enerojunio, Año 1 No. 2, pp. 177-193. [En línea]. Disponible en: https://www.gob.mx/shcp/pff/cee/documentos/revista-de-la-procuraduria-fiscal-de-la-federacion-ano-1-no-2263517 [Extraído el 9 de enero 2022].

Gamazo, J. (1994). Principales trabajos empíricos en materia de evasión fiscal. Anales de estudios económicos y empresariales, núm. 9, pp. 199-218. [En línea]. Disponible en: https://dialnet.unirioja.es/ejemplar/11257 [Consultado el 22 de noviembre del 2021].

García, F. (2002). Prohibición Constitucional de Confiscatoriedad y Deber de Tributación. Dykinson, Madrid.

Lara, J. (2007). Recaudador vs. Contribuyente: el juego de la evasión fiscal. Estudios Económicos, vol. 22, núm. 2, pp. 313-334.

Gutiérrez, M., (2021). Óptica empresarial sobre la materialidad de los actos para efectos fiscales. Revista de la Procuraduría Fiscal de la Federación. Enero-junio, Año 1 No. 2, pp. 289-305. [En línea]. Disponible en: https://www.gob.mx/shcp/pff/cee/documentos/revista-de-la-procuraduria-fiscal-de-la-federacion-ano-1-no-2263517 [Extraído el 9 de enero 2022].

Irigoyen, C., (2021). Introducción al artículo 69-B del Código Fiscal de la Federación. Revista de la Procuraduría Fiscal de la Federación. Enero-junio, Año 1 No. 2, pp. 91-120. [En línea]. Disponible en: https://www.gob.mx/shcp/pff/cee/documentos/revista-de-la-procuraduria-fiscal-de-la-federacion-ano-1-no-2263517 [Extraído el 9 de enero 2022].

León, N. (2018). Análisis de las Implicaciones Penales y Fiscales del Artículo 69-B del Código Fiscal de la Federación. Nuevo Consultorio Fiscal No. 689.

Ley de Firma Electrónica Avanzada. Publicada en el Diario Oficial de la Federación el 11 de enero del 2012. Última reforma publicada Diario Oficial de la Federación el 20 de mayo del 2021. [En línea]. Disponible en: https://www.diputados.gob.mx/LeyesBiblio/pdf/LFEA_200521.pdf [Extraído el 27 de noviembre 2021].

Ley General de Sociedades Mercantiles. Ley publicada en el Diario Oficial de la Federación el 4 de agosto de 1934. Última reforma publicada Diario Oficial de la Federación el 14 de junio del 2018. [En línea]. Disponible en: https://www.diputados.gob.mx/LeyesBiblio/pdf/144_140618.pdf [Extraído el 28 de noviembre del 2021].

Mendoza, E., et al (2017). Derecho Económico. IURE editores, Ciudad de México.

Mendoza, M. (2015). Interpretación sistemática de las partes que integran al artículo 69-B del CFF. Fiscoactualidades No. 8, IMCP, pp. 3-22. [En línea]. Disponible en: http://imcp.org.mx/wpcontent/uploads/2015/06/Fiscoactualidades-mayo_n\%C3\%BAm_08.pdf [Extraído el 02 de diciembre del 2021].

Murcia, L., Vega, C. y Sánchez, D. (2019). Alcance de las operaciones simuladas en México como un nuevo esquema para la evasión fiscal: un nuevo reto para el Estado. Horizontes de la Contaduría en las Ciencias Sociales. 
Julio-diciembre, No. 11, pp. 1-21. [En línea]. Disponible en: https://www.uv.mx/iic/files/2020/08/Num11Art01.pdf [Extraído el 8 de enero 2022].

Niño, D., (2021). Conceptos jurídicos fundamentales en el artículo 69-B del Código Fiscal de la federación. Revista de la Procuraduría Fiscal de la Federación. Enero-junio, Año 1 No. 2, pp. 261-288. [En línea]. Disponible en: https://www.gob.mx/shcp/pff/cee/documentos/revista-de-la-procuraduria-fiscal-de-la-federacion-ano-1-no-2263517 [Extraído el 9 de enero 2022].

Núñez, M. (2008). El Fenómeno de Lavado de Dinero en México. Causas, Efectos y Propuestas para Reforzar su Combate. Porrúa, México, D.F.

OCDE. Base de datos global de estadísticas tributarias. [En línea]. Disponible en: https://www.oecd.org/tax/taxpolicy/base-de-datos-global-de-estadisticas-tributarias.htm [Consultado el 28 de noviembre del 2021].

Ochoa, M. (2014). Elusión o Evasión Fiscal. Revista Iberoamericana de Contaduría, Economía y Administración, vol. 3 núm. 5, pp. 1-29. [En línea]. Disponible en: http://www.ricea.org.mx/index.php/ricea/article/view/19/35 [Extraído el 27 de noviembre del 2021].

ONU (2004). Convención de las Naciones Unidas contra la Delincuencia Organizada Transnacional y Sus Protocolos. [En línea]. Disponible en: https://www.unodc.org/documents/treaties/UNTOC/Publications/TOC\%20Convention/TOCebook-s.pdf [Extraído el 18 de noviembre del 2021].

Osorio, J. (2017). La Implementación de los Medios Electrónicos en Materia Fiscal en México. Revista Internacional LEGIS de Contabilidad y Auditoría. No. 70, pp. 81-106.

Osorio, J., \& Osorio L. (2019). La Presupuestación de las Principales Fuentes de Financiamiento del Gasto Público en México. Revista OIDLES, No. 27. [En línea]. Disponible en: https://www.eumed.net/rev/oidles/27/gastopublico-mexico.html [Extraído el 23 de noviembre del 2021].

Palma, F., (2021). Sobre la materialidad de las operaciones con efecto fiscal. Revista de la Procuraduría Fiscal de la Federación. Enero-junio, Año 1 No. 2, pp. 47-55. [En línea]. Disponible en: https://www.gob.mx/shcp/pff/cee/documentos/revista-de-la-procuraduria-fiscal-de-la-federacion-ano-1-no-2263517 [Extraído el 9 de enero 2022].

Real Academia Española. Diccionario del español jurídico. En línea]. Disponible en: https://dej.rae.es/lema/presunci\%C3\%B3n [Consultado el 19 de noviembre del 2021].

Ríos, G. (2003). Innovación Tecnológica en la Gestión Tributaria. Un Estudio Comparado: España y México. Boletín Mexicano de Derecho Comparado, nueva serie, año XXXVI No. 108, pp. 1011-1035.

Ríos, G. (2005). Las Infracciones Tributarias en el Sistema Tributario Mexicano. Boletín Mexicano de Derecho Comparado, nueva serie, año XXXVIII, núm. 114, pp. 1165-1186.

Ríos, G. (2006). Límites en el Acceso y Uso de la Información de la Base de Datos de la Administración Tributaria (Caso México). En Ríos G. ( $1^{\mathrm{a}}$ ed.). La Influencia de las Nuevas Tecnologías en el Derecho Tributario, pp. 161-183. México, D.F.

Rivera, J., (2021). Seguridad jurídica y derecho de audiencia de los EDOS en el artículo 69-B del Código Fiscal de la Federación. Revista de la Procuraduría Fiscal de la Federación. Enero-junio, Año 1 No. 2, pp. 225-259. [En línea]. Disponible en: https://www.gob.mx/shcp/pff/cee/documentos/revista-de-la-procuraduria-fiscal-de-lafederacion-ano-1-no-2-263517 [Extraído el 9 de enero 2022].

Roa, J., (2021). La materialidad de las operaciones para efectos fiscales: algunas reflexiones a partir de la sentencia correspondiente al expediente 1/17-erf-01-1. Revista de la Procuraduría Fiscal de la Federación. Enero-junio, Año 1 No. 2, pp. 71-90. [En línea]. Disponible en: https://www.gob.mx/shcp/pff/cee/documentos/revista-de-laprocuraduria-fiscal-de-la-federacion-ano-1-no-2-263517 [Extraído el 9 de enero 2022].

Rodríguez, B., (2021). La materialidad, la sustancia económica y la razón de negocios como elementos para acreditar la autenticidad de una operación. Revista de la Procuraduría Fiscal de la Federación. Enero-junio, Año 1 No. 2, pp. 195-224. [En línea]. Disponible en: https://www.gob.mx/shcp/pff/cee/documentos/revista-de-laprocuraduria-fiscal-de-la-federacion-ano-1-no-2-263517 [Extraído el 9 de enero 2022]. 
Rodríguez, G. (1995). Infracciones y Delitos Fiscales. Boletín Mexicano de Derecho Comparado, nueva serie, año XXVIII, No. 82, pp. 291-306.

Rodríguez, G. (2001). Evasión Fiscal. Boletín Mexicano de Derecho Comparado, vol. XXXIV, núm. 100, pp. 285-309.

Rodríguez, R. (2011). Derecho Fiscal. Oxford, México. D.F.

Sánchez, C., (2021). Comentarios en torno a la materialidad y el procedimiento contenido en el artículo 69-B del Código Fiscal de la Federación. Revista de la Procuraduría Fiscal de la Federación. Enero-junio, Año 1 No. 2 , pp. 121-136. [En línea]. Disponible en: https://www.gob.mx/shcp/pff/cee/documentos/revista-de-laprocuraduria-fiscal-de-la-federacion-ano-1-no-2-263517 [Extraído el 9 de enero 2022].

Sarduy, M. (2017). Enfoques de análisis de la evasión fiscal. Marco conceptual. Cofín Habana, vol. 12 núm. 2 , pp. 367 386. [En línea]. Disponible en: http://scielo.sld.cu/pdf/cofin/v11n2/cofin25217.pdf [Extraído el 28 de noviembre del 2021].

SAT. Datos abiertos. [En línea]. Disponible en: http://omawww.sat.gob.mx/cifras_sat/Paginas/inicio.html [Extraído el 18 de noviembre del 2021].

SAT. Proveedor de certificación de factura. [En línea]. Disponible en:

http://omawww.sat.gob.mx/tramitesyservicios/Paginas/proveedores_autorizados_certificacion.htm [Consultado el 30 de noviembre del 2021].

Torres, M. (2016). Teoría y Práctica de los Delitos Fiscales. Porrúa, México D.F.

Vela, A. (2015). Para Comprender la Importancia de la Prevención al Lavado de Dinero. PRAXIS de la Justicia Fiscal y Administrativa. No. 18 año VIII, pp. 1-18. [En línea]. Disponible en:

https://www.tfja.gob.mx/investigaciones/historico/pdf/paracomprenderlaimportanciadelaprevencionallavadode dinero.pdf [Extraído el 02 de diciembre del 2021].

Venegas, S. (2007). Presunciones y Ficciones en el Impuesto Sobre la Renta de las Personas Físicas en México. $1^{\text {a }}$ ed., Universidad Nacional Autónoma de México. México, D.F.

Venegas, S. (2010). Derecho Fiscal. Oxford, México D.F. 